\title{
Journalists' Language Awareness: Inferences from Writing Strategies
}

\author{
Daniel Perrin and Maureen Ehrensberger-Dow \\ Zurich University of Applied Sciences Winterthur \\ daniel.perrin@zhwin.ch / maureen.ehrensberger@zhwin.ch
}

\begin{abstract}
What journalists want to do is not always what they actually do as they sit at their computer workstations writing news based on source texts. This article focuses on journalists' writing behavior and their writing strategies in a sample of 17 case studies. Data was collected with progression analysis, a multi method approach combining ethnographic observation and interviews with computer logging and retrospective verbalizations. With this approach, it is possible to make inferences about the awareness journalists have of their language and their language use. The explorative findings show that there might be considerable differences between the professionally guided intentions of writers and their actions - a strong argument for multi-method approaches in production-oriented discourse analysis. Furthermore, the findings show clear differences between experienced and inexperienced journalists: the repertoires of the experienced journalists contain more writing strategies that are oriented to the management of the writing process and the design of the text function. Heightened language awareness may well be linked causally to writing success.
\end{abstract}

\section{Introduction}

What do journalists really do when they write? What are they trying to do - and why - and do they realize what they are doing? If a radio journalist becomes blocked in the middle of a text, does he have strategies to get back into the flow? Is a commentator aware that some of her citations no longer can be fairly attributed to her source because they have been 
edited so much that they are almost unrecognizable? Does a television journalist realize that he has inadvertently reversed the political orientation of a news agency report in translating it? All of these are routine events in journalism; the question of interest in the present article is how aware experienced and inexperienced journalists are of what they are doing and how they are using their language.

By 'language awareness', we mean that speakers consciously employ knowledge of language and language use and that they can articulate it. Language awareness affects the way language is used (cf. Häcki Buchofer, 2002), as exemplified in writing performance (Schoonen and De Glopper, 1996). Until recently, journalists' language awareness has been inferred from text products: Cottle (1998), for example, discusses text production in journalistic editing offices. Various studies have presumed language awareness on the part of professionals in media and members of other discourse communities based on the language and language-reflective comments in media products (e.g. Lehr, 2001; Spitzmüller, 2005).

By 'experienced' journalists we mean professionals with length, depth, and/or breadth of experience. These include professionals who have been working in media for many years and/or have a great deal of experience in multi-media and/or have a great deal of professional experience in topics somewhat removed from classic news journalism. By contrast, 'inexperienced' journalists have little and/or limited experience. In the latter case, they may have been working for quite a few years in media but do not research their own articles or write the final version themselves.

A number of studies investigating journalistic practice include observations, verbal protocols, or interviews with media professionals or editorial coaches (cf. Pitts, 1982; Laakaniemi, 1987; Dor, 2003; Herrman, 2005) - but without also systematically recording the text production itself. Only a few studies (e.g. Perrin, 2001; Sleurs et al., 2003) combine empirical data from writing processes, text products, and self-reflection by the writers into a vivid, multi-perspective picture of journalistic language awareness, its relation to journalistic expertise, and its function in text production.

The multi-method approach reported in Perrin (2001) was developed and applied for the first time within a qualitative and explorative investigation of journalistic writing in print, radio, TV, and on-line news offices in Switzerland (evaluations addressed to other research questions can be found in Perrin, 2005a; 2005b; Perrin and Ehrensberger, submitted). Data on writing processes were obtained from 40 workstations in media newsrooms and evaluated as case studies. Additional corpora on journalistic writing have since been collected, and various research projects have used or are using a multi-method approach to investigate writing in other domains: Boschung and Gnach (2003), for example, have investigated writing phases in a case study of academic writing, and Perrin (2006) has used findings from the present explorative field research as a pilot study for a Swiss national research project focused on the organizational language awareness of the Swiss national broadcasting company. The details of the approach used in these and the present explorative study are presented in the following section. 


\section{Progression analysis: A multi-method approach}

An approach that allows collection of data at journalists' workstations without affecting natural writing processes is progression analysis: it combines interviews, participatory observations, computer logging, discourse analysis, and cue-based retrospective verbal protocols. Every keystroke made during text production is recorded in computer logs and only after the deadlines, when texts are finished and submitted, are the computer logs reviewed and the journalists comment on what they have done. At the end of the analysis, there are data available on the work situation, the writing movements, the finished text, and the writing strategies of the person who produced the text. With this approach, it is possible to trace the awareness journalists have of their language and their language use.

Progression analysis is an ethnographic multi-method approach that qualitatively ascertains the regular use of language in natural situations by obtaining and relating to each other linguistic and extra-linguistic data from several perspectives and/or with several methods. These complement each other but also can produce contradictory findings. It is not used as a validation but rather as a multi-dimensional view. Denzin (1978) offers an early discussion of multi-method approaches and method triangulation; Aguado and Riemer (2001) present a more recent overview (see also Brewer and Hunter, 1989; Tashakkori and Teddlie, 2003; Flick, 2004). Progression analysis allows data to be obtained on three levels: the work situation, writing movements, and writing strategies. Before writing begins, details about the work situation are elicited with interviews and participatory observations; during writing, movements by the writers through the text developing on the computer screen are recorded in computer logs; and after writing, the repertoire of writing strategies is deduced from data-based retrospective verbal protocols (cf. Greene and Higgins, 1994; Perrin, 2003; Leander and Prior, 2004; Prior, 2004). The details of each level of progression are explained in more detail below.

\subsection{Situational analysis}

Before writing begins, the first level of progression analysis determines what the writing situation is and what experience the writer draws on for it. Some important factors are the writer's professional socialization and economic, institutional, and technological influences on the work situation as well as the specific writing task that a writer must accomplish. All of these are part of the real world and at the same time part of the mental representation that writers have of the world and that motivates their actions. Data on writers' self-perceptions are obtained in semi-standardized interviews: their biography, primarily in terms of their writing and professional experience, and their workplace. Participatory unstructured observations are also made of the editing process, as described in Tuchman (1991), Cottle (1998), and, in an overview, Gehrau (2002: 105-108).

A sample extract from the situational analysis for one of the case studies discussed in more detail further on (WW) might be: "a leading by-lined German-language weekly newspaper published in Switzerland". According to the comments by the journalist under 
investigation in an interview before any other data were collected, it orients itself to a demanding readership: infotainment (the combination of the communicative purposes of informing and entertaining) is not the goal. In journalistic practice, infotainment is a widespread and at the same time controversial means of gaining audience share, as indicated in Brants (1998). As shown in the progression analysis, though, this programmatic statement by the journalist contradicts some of the writing strategies he articulated later on (for a full discussion of this case study, see Perrin, 2005b). Preliminary interviews and observations can therefore provide some information about what writers intend to do and their awareness of why they want to do it, but not necessarily about their awareness of what they are actually doing.

\subsection{Writing movements}

During the writing process, the second level of progression analysis records every writing movement in a logging program that runs in the background behind a text editor. In larger investigations with progression analysis, logging programs run behind whatever editing programs writers usually use, for instance behind the user interface of news editing systems. The logging programs can follow the writing process over several workstations and do not influence the performance of the editing system.

Every movement and revision step can be represented as separate text versions and can be considered intermediate products of the writing process. In the WW case study already mentioned, the journalist started by writing two capital letters (see R0-R5 below for the English equivalents of the original German text). In the first revision (R1), he deleted the second letter and then wrote without interruption until "Teutsch-". In the next step, R2, he replaced the hyphen after "Teutsch" with a blank space and added "pilsner,". In step R3, the comma after "pilsner" was replaced by "_and". In steps R4 and R5, "race office" became "race office tent" and then the journalist completed the sentence with "making calls on cell phones". The various versions created throughout the writing process are listed below:

(R0) AF

(R1) After the race they all hang around in the smoke-filled race office, sipping tea or a Teutsch-

(R2) [...] race office, sipping tea or a Teutsch pilsner,

(R3) $\quad[\ldots]$ race office, sipping tea or a Teutsch pilsner and

(R4) $\quad[\ldots]$ race officetemt, sipping tea or a Teutsch pilsner and

(R5) [...] race office tent, sipping tea or a Teutsch pilsner and making calls on cell phones.

A much more concise representation of these steps can be obtained automatically from the logging data in so-called S-notation (see Kollberg and Severinson-Eklundh, 2001 for more details). Wherever a journalist interrupts a text to delete or add anything, S-notation inserts a break-character $(\mid)$ with a raised $\left({ }^{n}\right)$ or lowered $(n)$ number to indicate the order of the steps. Deleted passages are in "[square brackets $]^{\mathrm{n}}$ and later insertions in ${ }^{\mathrm{n}}\{\text { curly braces }\}^{\mathrm{n}}$. 
The steps in the example above would appear in S-notation as:

$\mathrm{A}^{1}\left[\left.\mathrm{~F}\right|_{1}\right]^{1}$ fter the race they all hang around in the smoke-filled race office $\left\{\mathrm{te}^{5}\left[\left.\mathrm{mt}\right|_{5}\right]^{5} \mathrm{nt}\right\}^{4}$, sipping tea or a Teutsch $\left[-\left.\right|_{2}\right]^{2}$ pilsner ${ }^{3}\left[,\left.\right|_{3}\right]^{3}$ and $\left.\right|_{4}$ making calls on cell phones. $\left.\right|_{6}$

The detail analysis of a writing event can be considerably simplified with S-notation, and the broader pattern can be traced in a progression graph, which shows how a writer moves through a developing text with a computer cursor. The temporal sequence of revisions in the writing process is represented on the ordinal scale of the horizontal axis; the spatial sequence of revisions in the text product is on the vertical axis, also ordinal. Represented in this way, the revisions describe a two-dimensional graph of text progression. In the extreme case, the graph is a straight line from the upper left to the lower right, representing a linear writing process without any jumps within the text. By contrast, the journalist in the example above did not move linearly in the first eleven steps of his writing process. He started writing the text (revisions 1-3 above), revised it and wrote the end (4-6 above), and then went back to add a beginning ("The red sun creeps behind the mountain", revisions 7-11).

The logs of writing movements, S-notation, and progression graphs provide information about what writers actually do during the writing process. These data can also be used to elicit explanations from the writers about the motivation for those movements and allow inferences to be made about their awareness of what they are doing, as described in more detail in the next section.

\subsection{Writing strategies}

The third level of progression analysis deduces the repertoire of a journalist's writing strategies once the writing process is over. 'Writing strategies' refer here to the reinforced, conscious, and articulable ideas of how decisions are made during the act of writing so that the text product has a great probability of taking on the intended form and fulfilling the intended function. 'Writing process' refers to the entire process of production of a text: it begins when a prospective writer realizes what the assignment is and ends when the writer passes the text on.

Preferably immediately after the writing process, journalists view how their texts came into being on the screen, either in real-time or in slow motion. While doing so, they continuously say what they did while writing and why they did it. An audio recording is made of this event-specific retrospective verbal protocol. With respect to the example above, the journalist explained that he had had the idea of beginning the text with "the red sun creeping behind the mountain" because the event he was writing about also started in the evening and he thought it would be funny to start with the sun, which was disappearing. One possibility for analyzing verbal protocols is to reduce the analytical content of the articulated strategies to their propositional content (cf. Perrin, 2001, $18 \mathrm{ff}$ ). This allows a categorization of the answers to the question of what the individuals under investigation are 
talking about and includes an interpretation of metaphors, something that is also addressed by Schmitt (2003). Explanations for actions in a writing process derive a propositional structure of the form $\mathrm{X} \bullet \mathrm{Y}$, where $\mathrm{X}$ represents the action, $\bullet$ a logical relationship, and $\mathrm{Y}$ an argument: "I do $\mathrm{X}$ because $\mathrm{Y}$ is true" or "I do $\mathrm{X}$ to achieve $\mathrm{Y}$ ". In these terms, the strategy mentioned above can be expressed as "Just start with an idea because it is funny". This third level of progression analysis opens a window onto the mind of writers, allowing inferences to be made about the strategies that guide writing processes, considerations writers might make, and the awareness writers have of what they are doing. The writing strategies that writers articulate certainly do not encompass all their strategies but do represent a significant portion of their repertoire of strategies. The multiple levels of progression analysis allow these to be placed in relation to the situational analysis and the findings on writing movements.

\section{Using progression analysis to access writing strategies}

The multi-method approach of progression analysis applied to a broad sample of writers working in various media can provide insight into the awareness journalists have of their language use. Writing research suggests that there are differences between experienced and inexperienced writers: those with more experience write with a heightened awareness of their actions, the writing process, and the text function. To put it succinctly, the assumption is that beginners produce texts and professionals control the process.

Although we cannot directly access whether experienced journalists really are more conscious of their writing process than inexperienced journalists are, progression analysis allows us to determine whether experienced journalists mention a greater number of more elaborate writing strategies, which would suggest a broader-based repertoire. It also allows us to ascertain whether experienced journalists mention more process-oriented strategies. If they justify their decisions more frequently in terms of the writing goal, plan, flow, and monitoring, then we can infer a more process-oriented repertoire. Finally, we can make some inferences about the relationship between writing experience and awareness of text function. If experienced journalists justify their decisions and actions related to the text product more frequently with reference to the function of a text than inexperienced journalists do, we can infer a more functionally-oriented repertoire of strategies.

These assumptions will be confirmed or refuted by examining journalistic newswriting produced in case studies from a major investigation of journalistic writing in print, radio, $\mathrm{TV}$, and on-line news offices in Switzerland - and on the strategies used by journalists in the process of writing to ensure that their text products are dramaturgically effective in terms of text function, meaning, structure, and language variant. The data were obtained using progression analysis as described in section 2 above. Although more than 4,000 revisions were logged, 170 writing strategies recorded, and 35 progression graphs drawn, there is no claim to representativeness or statistical significance. Since the study transmits and follows the standards of discourse analysis (e.g. Cotter, 2001) and not empirical 
sociological research, the findings from the case studies are used to make inferences about the language awareness of the journalists under investigation and not claims about journalists in general.

\subsection{Description of the sample}

The case studies under investigation here originated from the workstations of 17 journalists, all working in Switzerland and most writing in German, who differed in terms of experience, the kind of writing task they were engaged in, the type of news text they produced, and the medium they were working in. The cases are distributed over these four categories and their subdivisions as shown in Table 1.

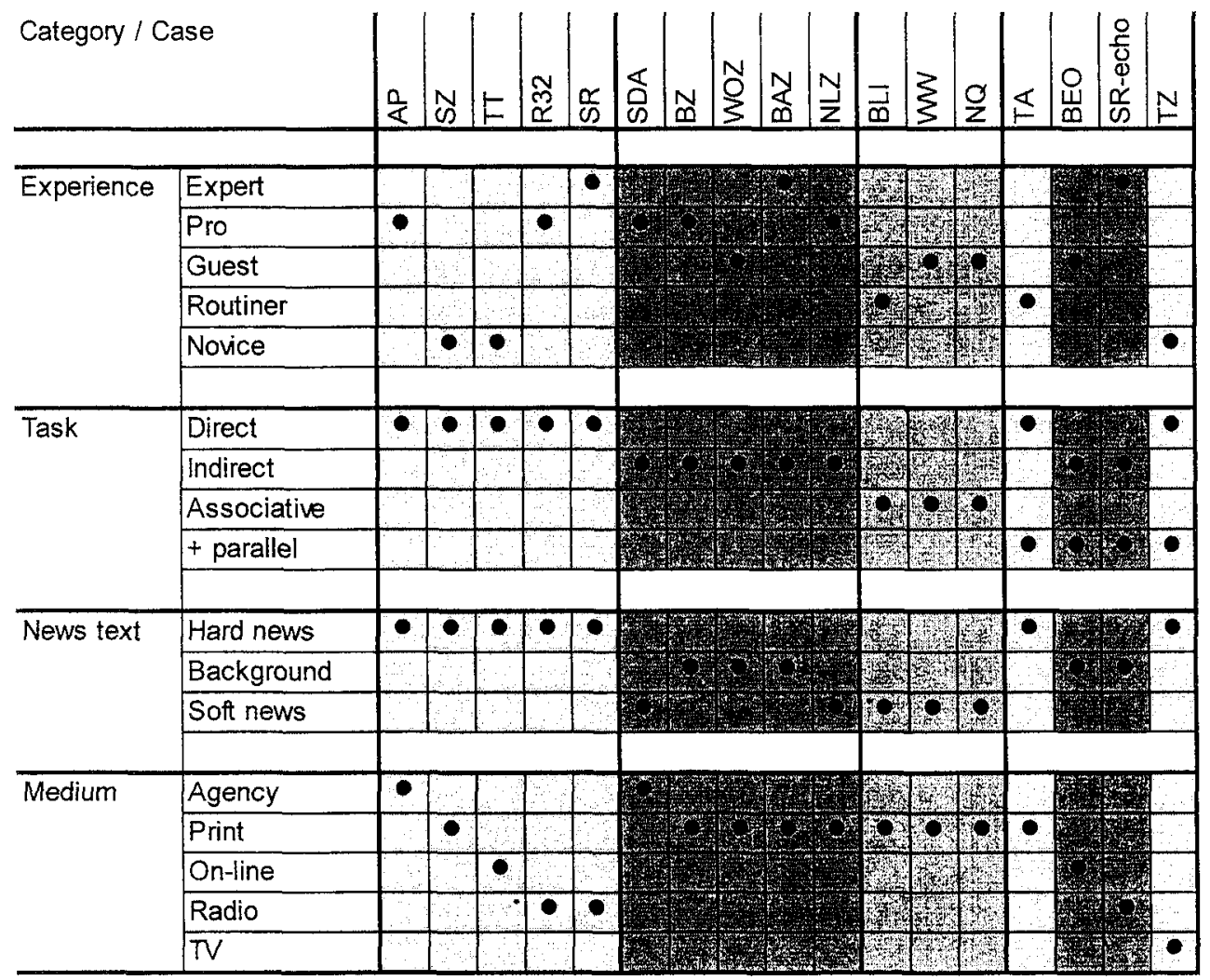

Table 1. Distribution of case studies according to experience, task, news text, and medium.

Experience. The experienced journalists in the case studies include 'experts' (with extensive professional experience in news journalism, working for a leading medium and/or with multi-media experience), 'pros' (with over five years of professional 
experience and research, responsible for their own contributions right up to the final proofreading phase), and 'guests' (with extensive professional experience in topics some distance removed from classical news journalism). The inexperienced journalists include so-called 'routiners' or routine writers (with in-depth but narrow experience doing routine writing who have been working for a long time but do not research or write the final version themselves) and 'novices' (with two or three years of professional experience, so lacking both depth and breadth). For example, a business journalist of a local newspaper (BAZ), with 25 years of experience in news journalism for television and newspapers, is an 'expert'. An Associated Press (AP) federal affairs correspondent with seven years professional experience in news journalism is a 'pro'. An experienced culture editor who has recently been writing for all of the sections of an on-line consumer ombudsman magazine (BEO) is a 'guest'. A tabloid's (BLI) chief reporter of society topics, whose texts are usually rewritten by editors, is a 'routiner'. And a Teletext (TT) editor with one year of experience is a 'novice'.

Task. In order to be able to compare writing processes and strategies, a distinction is made between direct text production (when writers electronically copy material from source texts), indirect text production (when they rephrase parts of texts from sources), and associative text reproduction (when they resort primarily to recalled source texts, writing and citing from memory) in addition to parallel text reproduction (when texts are created to accompany other texts). For example, a news editor of a radio station (R32), who copies a news agency report into his file and then shortens it, is reproducing text directly. A local editor of a city paper (BZ), who relies on his notes from a phone call for his writing, is reproducing text indirectly. A broadsheet (WW) society editor, who writes mainly from memory, is working associatively. A news editor from a television station (TZ), who fine tunes a source text to fit a picture, or an on-line magazine (BEO) editor, who writes his contribution as a portal to an existing hypertext network, are working directly or indirectly, respectively, as well as in parallel mode. Although not generalizable, it is noteworthy that all novices decide on direct text reproduction, whereas indirect or associative text reproduction is practiced by all of the guest writers - those authors with a great deal of experience outside of classic news journalism.

News text. The types of news texts refer to news in a broad sense: hard news (short and dealing with politically relevant, current topics), background texts (analysis of political topics over a greater expanse, setting them in context and going as far as possible towards a judgment; they correspond to the classic forms of report, analysis, and news feature), and soft news (covering society topics and curiosities from the uninspired to intellectually stimulating). An example of hard news is a text from a city newspaper (SOZ) about the current status of the Mossad affair. An analysis in a weekly paper (WOZ) about the Swiss genetic protection initiative is a background text, and a reportage in a broadsheet (WW) about a snowboard competition is soft news. As shown in Table 1, direct text reproduction occurs only for hard news, associative text reproduction only for soft news, and indirect text reproduction both soft news and background texts in these case studies.

Media. The texts in the 17 case studies were written for news agencies (AP: Associated 
Press, SDA: Schweizerische Depeschenagentur), print media (BAZ: Basler Zeitung, BLI: Blick, BZ: Berner Zeitung, NLZ: Neue Luzerner Zeitung, NQ: Nouveau Quotidien, SOZ: Solothurner Zeitung, TA: Tages-Anzeiger, WOZ: WochenZeitung, WW: Weltwoche), online media (BEO: Beobachter, TT: Teletext), radio (R32: Radio 32, SR-news: Swiss Radio DRS, news, SR-echo: Swiss Radio DRS, Echo der Zeit), or television (TZ: TeleZüri).

\subsection{Classification and coding of writing strategies}

Writing strategies can be either process-oriented or product-oriented. From a temporal perspective these relate either to potential, future processes and products or to those currently in progress. From a spatial perspective, they relate either to linear processes and products or to those that are hierarchically interconnected.

In the present article we classify process-oriented writing strategies as being directed to: the writing goal, such as knowing a lot about someone in order to be able to write with good variety; the writing plan, such as developing the concept of a text while recording and cutting the soundtracks; the writing flow, such as getting into the right flow by fiddling with the verbs in the first section; and monitoring the writing, such as printing a hard copy to proofread because it is easier to catch things that way. Product-oriented writing strategies are classified as being directed to: the text function, such as grabbing the reader with the beginning; the text meaning, such as choosing a word to describe something but not to exaggerate it; the text organization, such as providing an example before an explanation; and the language variant, such as changing words if they are not part of the local dialect.

In addition, we classify strategies according to their range. Process-oriented strategies can apply to: the writing process as part of a larger project, such as starting to write before reading the source text through; the writing process, such as just writing and then reducing and compressing later; or a phase of writing, such as working on a particular formulation until it is satisfactory. Product-oriented strategies can apply to: the text in its overall context, such as paraphrasing information so that it fits with a picture from the archives; the whole text, such as introducing new protagonists into the text before they appear in the original soundtrack; or a section of text, such as turning a main clause into subordinate clause in order to increase the tension.

Strategies are coded primarily according to the action referred to and not the argumentation. For example, a strategy such as "don't overload lead sentences with subordinate clauses because this makes them incredibly difficult to understand" is coded as "do not overload lead sentences", a strategy concerning text organization, and not as "do not hinder comprehension". Only if the content is part of the argument is the strategy coded for the overall sense of the action and argument. The strategy "change words when they are not part of the local dialect", for instance, is coded as "change unfamiliar words" and not just "change words".

What is coded is not the writer's comment per se but rather a propositionally condensed, tightened version, as described in section 2.3. If a writer verbalizes a writing action unclearly or ambiguously, the coding is refined with the data from the text 
production process. The preceding example is a tightened version of a comment along the lines of "I found out that you can say it that way in the Zurich dialect of German. In the report the word used was 'ended' but I couldn't have written 'Hostage drama in Texas ended' because it wouldn't have sounded right in this dialect".

\section{Findings}

The writing strategies articulated in the 17 case studies were classified, coded, translated into English, and grouped into the following sections according to whether they were process- or product-oriented. In addition, they were categorized as to what aspect of the process or the product they were directed to and the extent of their influence: within a broader context, within the writing process or text itself, and within a phase or section of those, respectively. The reference codes given at the end of each strategy listed in the tables below provide the source and sequence (see Perrin, 2001, for all of the strategies from the German verbal protocols).

\subsection{Process-oriented strategies}

Only experienced journalists mentioned elaborated strategies for the writing process and only experienced journalists mentioned strategies directed to the writing goal and writing flow. The process-oriented strategies of the inexperienced journalists are directed more to managing without a plan, checking details, and restarting after a total failure. The processoriented strategies are grouped into the following sections according to whether they relate to the writing goal, writing plan, writing flow, or monitoring and whether they extend over (a) the writing process as part of a larger project, (b) the actual writing process, or (c) a certain phase of the writing process.

Writing goal. With strategies directed to the writing goal, journalists focus on the sense of what they are doing and what they are trying to achieve. An example of a processoriented strategy related to the writing goal was expressed in the AP case study. An experienced federal affairs correspondent wrote three texts on the topic of humanitarian mine disposal in the course of one day: the first was a short notice that outlined the topic and indicated to the news agency clients that AP was following the current government affairs; the second was a daily report with the first important decisions in detail; and the third included finalized information and was submitted just before the evening deadline. The journalist wrote the short notice almost extemporaneously after just a quick look at the source text. It was very much a straightforward summary. She developed the second text, the daily report, from the short notice. The third text, the evening report, was full of jumps and digressions. It was not intended for the media public but rather as a source of information for the agency clients, the media editors, to show them how the situation had developed since the second text.

Step by step, the three texts observed the news agency's maxims of informing both 
quickly and thoroughly. The journalist's strategies enabled her to quickly and directly write a first text and then expand on it to provide more depth. The journalist moved away from the source text, clarified the focus in her mind, and established the overall organization of the text in the short notice. Later, when she dealt with details and copied in the source text to have in reserve, the overall goal was already determined and the direction of the writing process was clear.

In all of the 17 case studies under investigation here, only experienced journalists mentioned strategies related to the writing goal (see Table 2). They were concerned with securing sufficient knowledge about the topic before writing and avoiding problems with quoted sources after writing as well as gaining an overview by gathering relevant material together.

\begin{tabular}{|c|c|}
\hline Strategies related to writing goal & $\begin{array}{l}\text { Experience } \\
\text { level }\end{array}$ \\
\hline $\begin{array}{l}\text { a) over the writing process as part of a larger project } \\
\text { - Know a lot about someone so that the writing can be varied and repetition } \\
\text { avoided (NLZ.d) } \\
\text { - Use as much indirect speech as possible when citing so the source does not } \\
\text { retract everything (WOZ.m) }\end{array}$ & $\begin{array}{l}\exp \text { (Pro) } \\
\exp \text { (Guest) }\end{array}$ \\
\hline $\begin{array}{l}\text { b) over the actual writing process } \\
\text { (none mentioned) }\end{array}$ & \\
\hline $\begin{array}{l}\text { c) over a phase of the writing process } \\
\text { - Copy in passages in case you can use them (AP.e) } \\
\text { - Copy an agency notice into a file because the topic is the hit of the week } \\
\text { (R32.a) } \\
\text { - Copy a notice because it might supplement something previously copied } \\
\text { (R32.b) } \\
\text { - Include any strong impressions recorded on the notepad (WW.i) }\end{array}$ & $\begin{array}{l}\exp (\text { Pro) } \\
\exp \text { (Pro) } \\
\exp \text { (Pro) } \\
\exp \text { (Guest) }\end{array}$ \\
\hline
\end{tabular}

Table 2. Writing strategies related to writing goal classified by range and journalists' experience $(\exp =$ experienced, inexp $=$ inexperienced $)$.

Writing plan. With strategies directed to writing plan, journalists plan the chronological course of the writing process as a consequence of steps, episodes, stages, or phases. A process-oriented strategy related to the writing plan is exemplified in the SR-echo case study in which the experienced foreign correspondent prepared a script for radio about an election in Austria. In the text window, he added some notes to the sequence of seven soundtracks from his sources that he planned to play in the broadcast. This sequence determined the overall organization, and the correspondent moderated it by inserting his own text as transitions between them. He explained that he had worked out the concept for the whole script before the soundtracks were cut and sequenced.

The correspondent's strategies here served to form a text around source texts. In two decisive phases, he used the electronic aids carefully: first of all, he cut and ordered the soundtracks before he wrote the moderation text, so he would know how much time was 
left for moderation and what transitions had to be made. Secondly, he wrote and revised the moderation text in four stages, making a bridge from the beginning towards the end. By doing so, he kept the whole script in mind and the original plan was implemented in cycles of text movement.

In the case studies under investigation, strategies related to the writing plan were mentioned primarily by experienced journalists (see Table 3 ). Those directed to the process as part of a larger project focused on developing the concept of the text before and after doing research and linking reading with writing. Strategies during the actual writing process were concerned with incorporating material, developing a theme, and adding titles. Those directed to phases of the process focused on collecting materials or working out the beginning of the text.

\begin{tabular}{|c|c|}
\hline Strategies related to writing plan & $\begin{array}{l}\text { Experience } \\
\text { level }\end{array}$ \\
\hline $\begin{array}{l}\text { a) over the writing process as part of a larger project } \\
\text { - Develop the concept of the text while recording and cutting the } \\
\text { soundtracks (SR-echo.a) } \\
\text { - Start writing before the source text is completely read (AP.a) }\end{array}$ & $\begin{array}{l}\exp \text { (Expert) } \\
\exp (\text { Pro) }\end{array}$ \\
\hline $\begin{array}{l}\text { b) over the actual writing process } \\
\text { - Just start writing and then reduce and compress (SR-echo.d) } \\
\text { - Leave the title open to add later (AP.d) } \\
\text { - Write everything known at the beginning and then delete rather than } \\
\text { search for things afterwards (WOZ.c) } \\
\text { - Circle around a main focus to hang the story on (WW.g) } \\
\text { - Search through, sort, and copy the notes when working out a logical } \\
\text { sequence (WW.c) } \\
\text { - Keep clumps together that can be moved around later (WW.a) } \\
\text { - Record even the smallest thing and delete lots later (WW.j) } \\
\text { - Add the title at the end, perhaps from a citation or from the title of the } \\
\text { source text (TT.a) }\end{array}$ & $\begin{array}{l}\exp \text { (Expert) } \\
\exp \text { (Pro) } \\
\exp \text { (Guest) } \\
\exp \text { (Guest) } \\
\exp \text { (Guest) } \\
\\
\exp \text { (Guest) } \\
\exp \text { (Guest) } \\
\text { inexp (Novice) }\end{array}$ \\
\hline $\begin{array}{l}\text { c) over a phase of the writing process } \\
\text { - Before starting to write, call up on the screen everything written about the } \\
\text { topic (SDA.b) } \\
\text { - Add subtitles that come to mind when rereading word-for-word (SDA.f) } \\
\text { - Just type in quotes in the order they appear in the notes (WOZ.j) } \\
\text { - On the computer, reformulate even well-written passages from the notes } \\
\text { because they no longer fit the context (WOZ.e) } \\
\text { - Note down mental images immediately (WW.d) } \\
\text { - Have the beginning in mind before writing because it's the only place to } \\
\text { hook the reader (BLI.a) }\end{array}$ & $\begin{array}{l}\exp (\text { Pro) } \\
\exp \text { (Pro) } \\
\exp \text { (Guest) } \\
\exp \text { (Guest) } \\
\text { exp (Guest) } \\
\text { inexp } \\
\text { (Routiner) }\end{array}$ \\
\hline
\end{tabular}

Table 3. Writing strategies related to writing plan classified by range and journalists' experience (exp $=$ experienced, inexp $=$ inexperienced). 
Writing flow. Strategies directed to writing flow concern how journalists move through a text product as it develops. The BAZ case study provides a good example of process-oriented strategies related to writing flow: an experienced business journalist attended a media conference, worked out the central idea for his text on his drive back to the office, and established the organization in his mind. Back at his workstation, he quickly typed the text into the computer, referring occasionally to his notes. His goal was to write in a way that was both interesting for experts and understandable for the lay public. The strategies he expressed served to present the information in the text as appropriately, precisely, and comprehensibly as possible. While writing he had time for detailed language work because he had already thought through the sense, theme, and organization of the text and had the necessary background material at hand next to his computer. For detail work he used the computer like an extended thought process: he repeatedly reflected on and changed phrasing as he considered the text on the screen.

In the case studies, none of the inexperienced journalists mentioned strategies related to the writing flow (see Table 4). Many of the experienced journalists organized their overall work process to be able to step in and out of the flow of writing. Some of them consciously guided the flow of writing to keep moving forward and around obstacles, while during phases of writing some focused on shifting the location of the flow, jumping or avoiding parts, or changing the speed of the flow by reworking sections of text.

\begin{tabular}{|l|l|}
\hline Strategies related to writing flow & $\begin{array}{l}\text { Experience } \\
\text { level }\end{array}$ \\
\hline $\begin{array}{l}\text { a) over the writing process as part of a larger project } \\
\text { - Do research in order to be able to give the precise time (BZ.f) } \\
\text { - Do not endlessly modify the text but rather go through it once and then } \\
\text { get someone else to read it (NLZ.a) } \\
\text { - Get into the right flow by fiddling with the verbs in the first section } \\
\text { (WOZ.a) }\end{array}$ & $\begin{array}{l}\text { exp (Pro) } \\
\exp \text { (Pro) }\end{array}$ \\
- Always immediately check professions while writing or it might be \\
$\begin{array}{l}\text { forgotten (WOZ.g) } \\
\text { - Just start with an idea because it fits with the start of an event and is funny } \\
\text { (WW.b) }\end{array}$ & $\operatorname{exp~(Guest)~}$ \\
\hline $\begin{array}{l}\text { b) over the actual writing process } \\
\text { - Start writing a sentence even if it isn't known how it will look at the end } \\
\text { (NLZ.g) }\end{array}$ & $\operatorname{exp~(Pro)~}$ \\
- Write the text in a constant flow so that transitions work instead of \\
patching it together, which rips it out of context (NLZ.i) \\
- Put in quotation marks to indicate where a quote will go and fill it in later \\
$\begin{array}{l}\text { (WOZ.f) } \\
\text { - Fill in gaps in scenes with placeholders, or dots, at first (WW.h) }\end{array}$ & $\operatorname{exp~(Pro)~}$ \\
\hline $\begin{array}{l}\text { c) over a phase of the writing process } \\
\text { - Keep working on the formulation until you are happy with it (BAZ.a) } \\
\text { - Practice or try out things on the screen until the first sentence is pleasing } \\
\text { (SR-echo.c) }\end{array}$ & $\operatorname{exp~(Guest)~}$ \\
\hline
\end{tabular}




\begin{tabular}{l|l} 
- Write the final sentence in advance if it occurs to you (SDA.a) & exp (Pro) \\
- If the same word is used in a previous sentence, stop, jump back, and find & $\exp$ (Pro) \\
a synonym (SDA.d) & \\
- Jump to the end of the text to add a caption to a picture when it occurs to & $\exp$ (Pro) \\
you (SDA.g) & exp (Pro) \\
- Start a sentence over again when you get stuck writing (NLZ.j) & exp (Guest) \\
- Fix up the beginning if there are no more ideas for the rest or when the & \\
writing is not really flowing yet (WOZ.d) & exp (Guest) \\
- Start writing a new scene for the beginning if the previous attempt was not & so successful (WW.f)
\end{tabular}

Table 4. Writing strategies related to writing flow classified by range and journalists' experience $(\exp =$ experienced, inexp $=$ inexperienced $)$.

Monitoring. Journalists also use strategies to monitor the writing process and check the developing text. In the BEO case study, the guest journalist wrote a text for the magazine's website about sweet alcoholic drinks for young people. The text was based on an article in the print version of the magazine that he had written with a colleague. He used the print version as the source but not in electronic form; he typed in a short website text, including hyperlinks to other texts on the magazine's site and other sites. When the text had reached about three-fifths of its final form, the journalist checked which points had already been included and which still had to be added. By typing in the online version of the text, the journalist saved himself the tedium of revising electronic chunks of text and made it easier to add hyperlinks in logical places. Before he had filled the available space, he used his previously prepared list of hyperlinks to ensure that all the points had been covered and then inserted links and added any text that was needed. The electronic text links thus served as a monitor for the linear writing process.

In the case studies, the only monitoring strategies related to the overall project were mentioned by inexperienced journalists and focused on getting details correct and quickly finishing or repeating the writing process (see Table 5). Many of the strategies by experienced journalists were directed to constantly monitoring the actual writing process, avoiding risks, and overcoming insecurity. Some of the investigated journalists expressed strategies for proofreading and correcting their texts in a separate editing phase and for obtaining a certain distance to their texts.

\begin{tabular}{|l|l|}
\hline Strategies related to monitoring & $\begin{array}{l}\text { Experience } \\
\text { level }\end{array}$ \\
\hline $\begin{array}{l}\text { a) over the writing process as part of a larger project } \\
\text { - Record names and dates correctly because it's embarrassing to get them } \\
\text { wrong (BLI.e) }\end{array}$ & $\begin{array}{l}\text { inexp } \\
\text { (Routiner) } \\
\text { - Throw away a poorly organized article and write it over again (TT.f) }\end{array}$ \\
\hline $\begin{array}{l}\text { b) over the actual writing process } \\
\text { - Correct a comment when it is apparent that the first version is based on a } \\
\text { misinterpretation (SR.l) } \\
\text { - Include a source text that arrives during the writing process (AP.h) }\end{array}$ & $\begin{array}{l}\exp \text { (Expert) } \\
\text { exp (Pro) }\end{array}$ \\
\hline
\end{tabular}




\begin{tabular}{|l|l|} 
- Do not switch around sections in the text because that complicates things & exp (Pro) \\
(NLZ.c) & exp (Pro) \\
- Check the electronic text archive while writing even though before & \\
writing it was obvious there wasn't much there (SDA.c) & exp (Pro) \\
- Try out on the screen which linking word works well (BZ.d) & exp (Guest) \\
- Try various formulations out on the screen to see how they look (WOZ.h) & exp (Guest) \\
- Carefully check the function of the questioned experts when typing in the & \\
text (WOZ.k) & exp (Guest) \\
- Before the end, check what still has to be added (BEO.b) & $\begin{array}{l}\text { inexp } \\
\text { - Always correct typing mistakes immediately (BLI.c) }\end{array}$ \\
- While writing, notice when people will have had enough (BIL.g) & $\begin{array}{l}\text { inexp } \\
\text { (Routiner) }\end{array}$ \\
- After discussing it, accept a colleague's suggestion for a formulation & inexp (Novice) \\
(SZ.i) & \\
\hline c) over a phase of the writing process & exp (Pro) \\
- Make a hard copy to proofread because many things are only noticeable \\
then (R32.k)
\end{tabular}

Table 5. Writing strategies related to monitoring the writing process classified by range and journalists' experience (exp=experienced, inexp=inexperienced).

\subsection{Product-oriented strategies}

Both inexperienced and experienced journalists mentioned strategies for the writing product but only the former mention elaborated strategies for text function. The product-oriented strategies are grouped into the following sections according to whether they relate to the text function, meaning, structure, or type and whether they extend to (a) the text within a larger context, (b) the text itself, or (c) a section of the text.

Text function. Text function refers to the communicative effect writers intend their text to have. In the WW case study mentioned in Section 2, the experienced journalist formulated various strategies related to his sources for the development of the function of his text (see Perrin, 2005b, for more details). He did not follow the chronology of events, the standards of a particular genre, or the routine of an established production process. Much more, he developed his own dramaturgy, searching for a suitable form, circling towards a main focus, and recombining parts of the text. With his writing strategies, the journalist radically subjugated the text to his main focus, to his dramaturgical idea, and to his story. In doing so, he also altered the comments made by his sources. This began with 
the usual journalistic considerations of how spoken comments should be represented in writing: the journalist talked about 'condensing' remarks made by his sources. Above and beyond that, though, he put words in the mouths of his text protagonists that were plausible but 'invented'.

Other journalists in the case studies, most of them also experienced, mentioned strategies related to the function of a text over various ranges (see Table 6). In a larger context, strategies concerned citing sources and interaction with other texts. Extended over the range of the text itself strategies were focused on capturing the readers' interest, entertaining them, and incorporating central themes. In several case studies, journalists mentioned strategies dealing with the function of sections of the text, such as incorporating and adapting quotes, and linking scenes and various topics with the central theme.

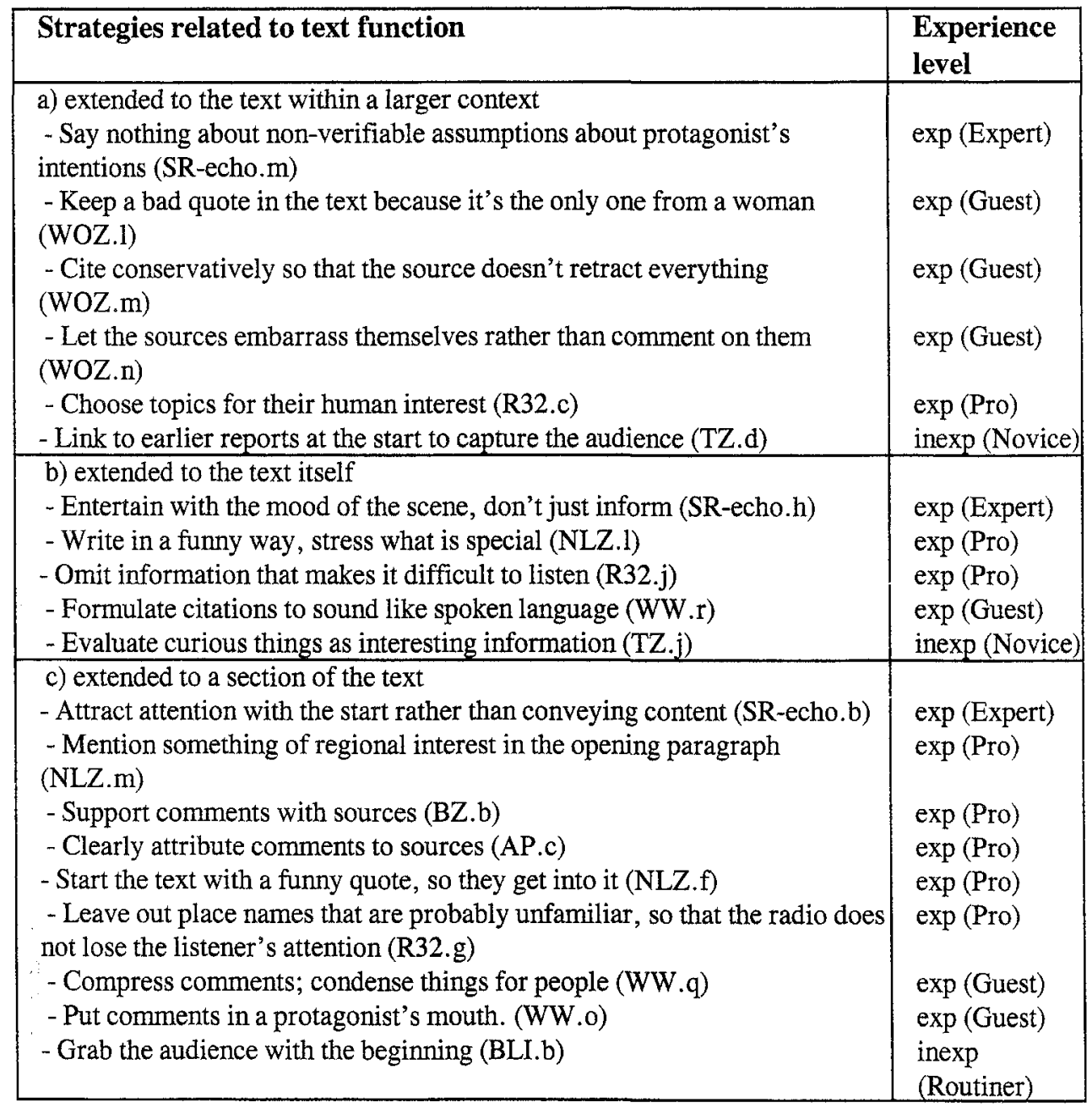


- Do not judge (TA.a)

inexp

(Routiner)

Table 6. Writing strategies related to text function classified by range and journalists' experience $(\exp =$ experienced, inexp $=$ inexperienced $)$.

Text meaning. Strategies directed to text meaning focus on the ideas and thoughts that a text is meant to activate in its recipients. An example of a product-oriented strategy focused on the meaning of a text was given in the BAZ case study mentioned in section 4.1, when the experienced business journalist explained that one of his revisions was because he had decided not use an official's complicated title. This was a clear strategy that cost him little time or effort since the revision consisted of deleting a single letter. The strategy as expressed by the journalist was to present the information in the text as appropriately, precisely, and comprehensibly as possible.

With strategies directed to meaning (see Table 7), both experienced and inexperienced journalists focused on ideas about objects, scenes, protagonists, or other parts of the text. Extended to the text within a larger context, these include filling in information gaps, simplifying, and staying vague. Within the text itself, the journalists focused on linking their texts to their readers' existing knowledge, highlighting significant or unusual features, and omitting unnecessary details. In sections of the text, strategies focused on precision and clarity of expression as well as careful choice of words.

\begin{tabular}{|l|l|}
\hline Strategies directed to text meaning & $\begin{array}{l}\text { Experience } \\
\text { level }\end{array}$ \\
\hline a) extended to the text within a larger context & exp (Expert) \\
- Fill gaps in the source text with own knowledge (SR.e) & $\operatorname{exp~(Expert)~}$ \\
- Cover up for knowledge gaps with vague statements (SR.k) & expo) \\
- Remain general and correct rather than precise and wrong (BZ.a) & exp (Pro) \\
- Provide the precise time (BZ.f) & inexp \\
- Fill research gaps with information from other media (BZ.g) & inexp (Novice) \\
- Orient the text to the chosen pictures (BLI.f) & inexp (Novice) \\
- Just pick one variant if the source text is ambiguous (TT.d) & inexp (Novice) \\
- Introduce information from another media product as facts (TZ.f) & inexp (Novice) \\
- Dramaturgically fine tune the text to suit the pictures (TZ.i) & \\
- Highlight information we have a picture for (TZ.g) & exp (Expert) \\
\hline b) extended to the text itself & exp (Expert) \\
- Consciously assume the audience has prior knowledge - or provide it & exp (Expert) \\
- Put into own words what the source said with hedges and qualifications & exp (Pro) \\
- Correct one's own misinterpretation (SR.1) & exp (Guest) \\
- Remove a stupid construction from a quote and restate it indirectly (BZ.e) \\
- Translate source text so that it's clear to the reader what is meant (NQ.b) \\
- Remove numbers because they just confuse things (TT.e) & inexp (Novice) \\
\hline c) extended to a section of the text & \\
\hline
\end{tabular}


- Describe a thing with the selected words, don't exaggerate it (SR.h)

- Be aware what a word means (SR.p)

- Sacrifice correct titles for officials for more understandable labels (BAZ.b)

- Adapt time references ('yesterday') to the publication date (R32.d)

- Avoid complicated formulations such as 'two goals down twice' (R32.h)

- Avoid clichés (NQ.e)

- Label things in concrete terms instead of describing them abstractly

(NQ.f)

- Be sure to make it clear who the pronoun 'they' refers to (NQ.g)

- Leave the 'simplest' of two synonymous expressions (WOZ.q)

- Try to use the precise term in the legend for the object in the picture (SZ.h)

- Assume a term is well-known because it is a current media topic (TZ.a)

- Choose a formulation that assumes a lot of foreknowledge but is short (TT.b)

Table 7. Writing strategies directed to text meaning categorized by range and journalists' experience (exp $=$ experienced, inexp $=$ inexperienced $)$.

Text structure. Text structure refers to the order and links in a text, for example of the words, sentences, and paragraphs; of the protagonists and scenes; and of the narrative present and past. In one of the case studies (BLI), a routine writer prepared a report about the latest news of the 'big names' at an event attended by prominent individuals. In the process of writing, he made two rather significant revisions, the first concerning the appearance of protagonists and the second concerning the integration of quotes. The strategy the writer used was to link brief appearances of prominent protagonists, as much as possible naming them at the beginning of sentences to make the frequent change of the main players clear. For the same reason, he avoided placing quotes from two sources next to each other without any moderation. He did not mention any broader-ranging structural strategies; he selected the main players and ordered their appearance in an absolutely linear composition.

Although only one of the journalists in the case studies mentioned strategies extended to the text within a larger context, many strategies directed to text structure were mentioned with respect to the text itself. Both experienced and inexperienced journalists used them to break up a plot for the narrative, order appearances of protagonists, induce abstractions from the concrete, and prepare for shifts in focus. Within sections of texts, the strategies focused on ordering, linking, and keeping structures simple, avoiding unnecessary repetition, and using a variety of expressions.

\begin{tabular}{|l|l|}
\hline Strategies directed to text structure & $\begin{array}{l}\text { Experience } \\
\text { level }\end{array}$ \\
\hline $\begin{array}{l}\text { a) extended to the text within a larger context } \\
\text { - Avoid repeating words, write with variety (NLZ.d) }\end{array}$ & exp (Pro) \\
\hline b) extended to the text itself & \\
\hline
\end{tabular}


- Work with repetitions in spoken text (SR.o)

- Introduce new players into the text with indefinite articles (SR.c)

- Only say very important things several times (SR.echo.g)

- Introduce a new protagonist into a text before he appears in the original soundtrack (SR.echo.i)

- Get past the hook in the third sentence of the lead (AP.g)

- Sacrifice filler words and details if the lead is too long (AP.i)

- Keep brief (R32.i)

- Contrast perspectives to each other, like shooting a film (WW.e)

- Stretch contrasts with and within the scenes as a central theme (WW.k)

- Connect the story to an extract (WW.m)

- Introduce protagonists in a text (WW.I)

- Provide the example before the explanation (NQ.h)

- Start sentences and paragraphs with names of prominent people (BLI.h)

- Shorten or lengthen the end of the text until the last line is long enough

(TA.b)

- Eliminate redundant information (SZ.b)

- Carefully summarize the text in a sub-title (SZ.f)

- Answer the wh-questions early on and clearly (TZ.e)

- Repeat the name of a main role instead of describing it (TZ.m)

c) extended to a section of the text

- Don't overload lead sentences (SR.j), for example with embedded subordinate clauses (SR.b)

- Don't overload a sentence with a calendar date (SR.f)

- Insert a subordinate clause to get some movement into a sentence (SR.g)

- Put a list of things in a logical order (SR.i)

- Formulate the first sentence without any subordinate clauses (AP.b)

- Change the formulations in successive announcements (AP.f)

- Don't repeat words because that sounds stupid on radio (R32.e)

- Vary the verbs, because the text lives from the verbs (NLZ.h)

- Vary the words (BZ.h),

(SDA.d),

(NQ.C),

(WOZ.o)

- Turn a main clause into a subordinate clause to raise the prosodic tension (BEO.a)

- Avoid using too many nouns because they are not so nice (WOZ.i)

- Vary the rhythm of two successive sections (WOZ.p)

- Integrate minor scenes or leave them out (WW.n)

- Introduce and prepare for citations in text (NQ.k)

- Edit quotes from different sources so they don't immediately follow each other (BLI.28)

- Don't put any more relative clauses into a sentence that is already complex; instead, add the information to the end (TZ.1)

$\exp$ (Expert)

$\exp$ (Expert)

$\exp$ (Expert)

$\exp$ (Expert)

$\exp$ (Pro)

$\exp ($ Pro)

$\exp ($ Pro)

$\exp$ (Guest)

$\exp$ (Guest)

$\exp$ (Guest)

$\exp$ (Guest)

$\exp$ (Guest)

inexp

(Routiner)

inexp

(Routiner)

inexp (Novice)

inexp (Novice)

inexp (Novice) inexp (Novice)

$\exp$ (Expert)

$\exp$ (Expert)

$\exp$ (Expert)

$\exp$ (Expert)

$\exp$ (Pro)

$\exp$ (Pro)

$\exp$ (Pro)

$\exp$ (Pro)

$\exp$ (Pro)

$\exp$ (Pro)

$\exp$ (Guest)

$\exp$ (Guest)

$\exp$ (Guest)

$\exp$ (Guest)

$\exp$ (Guest)

$\exp$ (Guest)

$\exp$ (Guest)

inexp

(Routiner)

inexp (Novice) 
- Shorten the lead to the prescribed maximum length (SZ.a)

- Put in sub-titles so the column breaks are nicer (SZ.c)

- Eliminate text so that the next sub-title does not look bad (SZ.d)

- Choose the words so there is room for the title (SZ.e)

- Don't use the same word in the title and the sub-title (SZ.g)

inexp (Novice) inexp (Novice) inexp (Novice) inexp (Novice) inexp (Novice)

Table 8. Writing strategies related to text structure classified by range and journalists' experience $(\exp =$ experienced, inexp $=$ inexperienced $)$.

Language variant. Variant of language refers to the register within a sociolect within a natural language. Spoken variants of German in Switzerland include, for example, the non-judgmental, formal, standard language and local Swiss German dialects. In the TZ case study, a novice journalist had two hours to choose six brief announcements from various sources and prepare them for a private television station newscast. He had to shorten the texts, adapt them to pictures from the station's archives, and convert them to the spoken dialect. While the journalist worked on the text on the computer screen, the meaning of the passage shifted and the understanding of the original version seemed to fade. The final result had a different political orientation from the original. However, even in retrospect, the journalist justified his decisions in terms of language variant and style. In the case studies, the strategies directed to language variant extended to the text itself and sections of the text but not to the text within a larger context, such as the journalistic appropriateness of the variant used (see Table 9). At the text level, experienced journalists focused on avoiding redundancy and using language economically. Within sections of text, both experienced and inexperienced journalists' strategies focused on choosing the right variant in terms of dialect, localization, level of formality, and mode.

\begin{tabular}{|c|c|}
\hline Strategies directed to language variant & $\begin{array}{l}\text { Experience } \\
\text { level }\end{array}$ \\
\hline $\begin{array}{l}\text { a) extended to the text within a larger context } \\
\text { (none mentioned) }\end{array}$ & \\
\hline $\begin{array}{l}\text { b) extended to the text itself } \\
\text { - Avoid pleonasms (BZ.i) } \\
\text { - Be economical; use concise, clear, and precise formulations instead of } \\
\text { ornate ones (NQ.d) }\end{array}$ & $\begin{array}{l}\exp \text { (Pro) } \\
\exp \text { (Guest) }\end{array}$ \\
\hline $\begin{array}{l}\text { c) extended to a section of the text } \\
\text { - Choose elegant instead of genteel language (SR.n) } \\
\text { - Translate 'federal German' expressions into Swiss standard German } \\
\text { (SR.m) } \\
\text { - Rely on own language intuitions, even against the grammatical rules } \\
\text { (SR.a) } \\
\text { - Compose rough initial ideas ('bitching') in moderate terms (SR.echo.k) } \\
\text { - Write in the active voice (NLZ.k) } \\
\text { - Avoid expressions that work when spoken but not when written (NQ.j) } \\
\text { - Replace words that sound high German with Swiss-German words used in } \\
\text { the local dialect (TZ.h) }\end{array}$ & $\begin{array}{l}\exp \text { (Expert) } \\
\exp \text { (Expert) } \\
\exp \text { (Expert) } \\
\exp \text { (Expert) } \\
\exp \text { (Pro) } \\
\exp \text { (Guest) } \\
\text { inexp (Novice) }\end{array}$ \\
\hline
\end{tabular}


- Verbally translate a nominalization in the source text because it's not used $\mid$ inexp (Novice) in the local dialect (TZ.c)

- Try to use correct, complex syntax with reflexive modal verbs (TZ.k)

- Put a verb in the title because the chief editor wants it that way (TZ.b)

inexp (Novice) inexp (Novice)

Table 9. Writing strategies related to language variant classified by range and journalists' experience (exp=experienced, inexp=inexperienced).

\section{Conclusions}

The strategies discussed in the previous section are oriented to either the process of writing or the dramaturgy of the text product: many journalists seem aware of how the writing process works and what makes a text work well. As they write, they apply various strategies and are so conscious of them that they can verbalize them to justify their actions. Each journalist's repertoire of verbalized strategies has a different focus (see Perrin, 2001, for the complete lists), but there are some similarities based on the experience journalists bring to the writing task.

Experienced journalists seem much more aware of what they are doing during the writing process: they express process-oriented strategies far more often than inexperienced journalists do. These strategies refer to the writing goal, plan, flow, and monitoring and extend over the writing process as part of a larger project, the actual writing process, and to phases of the writing process. Journalists use these strategies to plan and guide the writing process, for example, to avoid tangents and complete texts on time. Not only do the experienced journalists have more precise ideas of the effect the text dramaturgy should have, they have better strategies at their disposal to recognize and overcome problems while writing.

Experienced journalists plan their texts before starting to write and tend to revise them in several complete passes, consciously separated by a certain distance. They mention a rich repertoire of strategies for the writing process and also seem to use them. For example, many experienced journalists are aware of the possibilities of computer technology and use it in a sophisticated way by trying things out and fitting parts of text together, using it as a supplier of material and organization or as a text editor after the text is already planned. The inexperienced journalists, by contrast, do not mention anything about the computer as a writing tool and lose time and perspective by copying and pasting text fragments and jumping back and forth to correct small sections of text. By being more conscious of writing techniques and the writing process, experienced writers perceive that they achieve better text results for comparable tasks more directly (e.g. SR vs. TZ or BAZ vs. SZ).

A main assumption of writing research (cf. Levy and Ransdell, 1996; van Waes and Schellens, 2003) is that writing processes show patterns or recurring combinations of features. Among the strategies mentioned by the experienced journalists investigated in the present paper, patterns can be observed in individual writing processes that differentiate one writer from another. Some writing processes flow in the direction that the final product will be read, others in the opposite direction. One journalist might fiddle with verbs while 
another circles broadly around entire formulations. A text might be practically finished in one go or might develop over several attempts. One writer might strive to use synonyms while another purposely always chooses the same word to describe a certain thing.

Patterns of process-oriented strategies typical of individuals are also mentioned in the case studies in which experienced journalists write several texts after each other. For example, in several writing processes one writer tries to fill information gaps in the source texts with his own knowledge and express himself in a way that the audience probably understands. Another journalist begins writing an initial text before she has gathered all the information.

However, there are also patterns of strategies that are valid for all of the writing processes examined. Most of the strategies mentioned relate ultimately to optimizing communication: achieving the greatest possible communicative success with the least possible effort. In all cases, process-oriented strategies are used to direct, organize, push forward, and monitor the writing process.

Product-oriented strategies are directed to sensible function, meaning, structure, and register of a text, its sections, and its language. Both experienced and inexperienced journalists demonstrate their awareness of the intended text product and refer to productoriented strategies, but the experienced writers in these case studies refer to far more strategies in more areas of language use than inexperienced writers do. The pattern is most noticeable in the area of language function, where 17 of the 21 writing strategies were mentioned by experienced writers, along with clusters of strategies in certain sub-areas of text meaning and text structure. Only with reference to language variant did the inexperienced writers mention a proportionately similar number of strategies.

The inferences of language awareness from the writing strategies expressed by the journalists in this study are preliminary and not statistically significant but do provide some answers to the initial questions. In general terms, it seems that experienced writers are more aware of their writing processes and consciously use more functionally-oriented strategies than inexperienced journalists do. What happens in the minds of writers has to be inferred retrospectively, and some methodological reservations exist: stimulated by computer video recordings of their writing process, the journalists in the case studies verbalized strategies that they might have used in such a situation although they may not necessarily be the ones they actually used. What is noteworthy about our findings is that they provide support for the assumptions of previous writing research in two new areas: for writing at the workplace and for the domain of news journalism.

It may well be that many other writers in similar situations to the journalists in these case studies use similar strategies and that there is such a thing as typical, domain-specific writing. What the similarities and differences are and what they have to do with the work situation, the text product, and ultimately the communicative success of the journalistic writing remains to be investigated. The process of articulating their strategies certainly seemed to heighten these journalists' awareness of what they were doing while writing and triggered a desire in some of them to search for other, more appropriate strategies and to develop a broader, more flexible repertoire. Similar observations have been made 
elsewhere (cf. van Waes and Schellens, 2003) and prompted the recommendation that professional writers should be made more aware of their actions and encouraged to expand their repertoire of writing strategies by using professionally developed, research-based techniques.

\section{References}

Aguado, Karin and Claudia Riemer (2001): "Triangulation: Chancen und Grenzen mehrmethodischer empirischer Forschung" [Triangulation: Possibilities for and limitations of multi-method empirical research]. In K. Aguado and C. Riemer, eds., Wege und Ziele. Zur Theorie, Empirie und Praxis des Deutschen als Fremdsprache (und anderer Fremdsprachen). Festschrift für Gert Henrici zum 60. Geburtstag. Baltmannsweiler: Schneider Hohengehren, 245-257.

Boschung, Detlev and Aleksandra Gnach (2003): Navigation und Werkzeuggebrauch als Indikatoren für die Phasierung von wissenschaftlichen Schreibprozessen am Computer [Navigation and tool use as indicators of the phases of academic writing processes on the computer]. Unpublished Thesis. Bern: University of Bern.

Brants, Kees (1998): “Who is afraid of infotainment?". European Journal of Communication 30: 315-336.

Brewer, John and Albert Hunter (1989): Multimethod research. A synthesis of styles. Newbury Park: Sage.

Cotter, Colleen (2001): "Discourse and media". In D. Schiffrin, D. Tanner, and H.E. Hamilton, eds., The Handbook of Discourse Analysis. Oxford: Blackwell, 416-463.

Cottle, Simon (1998): "Participant observation: Researching news production". In A. Hansen, S. Cottle, Ch. Newbold, and R. Negrine, eds., Mass communication research methods. Houndsmill: Macmillan, 35-65.

Denzin, Norman K. (1978): The research act. $2^{\text {nd }}$ edition. New York: McGraw-Hill.

Dor, Daniel (2003): “On newspaper headlines as relevance optimizers". Journal of Pragmatics 35: 695-721.

Flick, Uwe (2004): Triangulation. Wiesbaden: Verlag für Sozialwissenschaften.

Gehrau, Volker (2002): Die Beobachtung in der Kommunikationswissenschaft [Observation in communication studies]. Konstanz: UVK.

Greene, Stuart and Lorraine Higgins (1994): "Once upon a time': The use of retrospective accounts in building theory in composition". In P. Smagorinsky, ed., Speaking about writing. Reflections on research methodology. Newbury Park, CA: Sage, 115-140.

Häcki Buchofer, Annelies (2002): "Steuert Sprachbewusstheit den eigenen Sprachgebrauch? Überlegungen zum Zusammenhang an Beispielen aus der deutschen Schweiz" [Does language awareness guide language use? Considerations on the connection with examples from Germanspeaking Switzerland]. Der Deutschunterricht 54: 18-30.

Herrmann, Friederieke (ed.)(2005): Vom Leiden am Schreiben. Was auch erfolgreiche Journalisten quält. Erfahrungen und Übungen [Of suffering while writing. What also tortures successful journalists. Experiences and exercises]. Opladen, VS: Verlag für Sozialwissenschaften.

Kollberg, Py and Kerstin Severinson-Eklundh (2001): "Studying writers' revising patterns with 
S-notation analysis". In G. Rijlaarsdam, series ed., and T. Olive and C.M. Levy, vol. eds., Studies in Writing: Vol. 10. Contemporary tools and techniques for studying writing. Dordrecht: Kluwer Academic, 89-104.

Laakaniemi, Ray (1987): "An analysis of writing coach programs on American daily newspapers". Journalism Quarterly 2-3: 567-575.

Leander, Kevin and Paul Prior (2004): "Speaking and writing. How talk and text interact". In C. Bazerman and P. Prior, eds., What writing does and how it does it: An introduction to analysis of text and textual practice. Mahwah, NJ: Lawrence Erlbaum, 201-238.

Lehr, Andrea (2001): "'Überdosis Sprache'. Ein Panoptikum sprachreflexiver Äußerungen in Pressetexten' ['Language overdose'. A collection of language-reflective comments in press texts]. In A. Lehr, M. Kammerer, K.-P. Konerding, A. Storrer, C. Thimm, and W. Wolski, eds., Sprache im Alltag. Beiträge zu neuen Perspektiven in der Linguistik. Herbert Ernst Wiegand zum 65. Geburtstag gewidmet. Berlin: de Gruyter, 321-348.

Levy, C. Michael and Sarah Ransdell (1996): "Writing signatures". In C.M. Levy and S. Ransdell, eds., The science of writing. Theories, methods, individual differences and applications. Mahwah, N.J.: Lawrence Erlbaum, 127-148.

Perrin, Daniel (2001): Wie Journalisten schreiben. Ergebnisse angewandter Schreibprozessforschung [How journalists write. Results from applied writing process research]. In C. Mast and S. Russ-Mohl, vol. eds., Journalismus: Vol. 40. Konstanz: UVK.

(2003): "Progression analysis (PA): Investigating writing strategies at the workplace". In D. Perrin, ed., The pragmatics of writing [Special Issue]. Joumal of Pragmatics 35: 907-921.

. (2005a): "Zwischen Vermittlung und Instrumentalisierung: Die Rekontextualisierung im Mediendiskurs" [Between mediation and instrumentalization: Recontextualization in media discourse]. In E.-M. Jakobs, K. Lehnen, and K. Schindler, eds., Schreiben am Arbeitsplatz. Wiesbaden, Verlag für Sozialwissenschaften, 153-178.

. (2005b): "Den Leuten die Sachen verdichten" - Kreativ schreiben unter Druck" ['Compress things for people' - Creative writing under pressure]. In K. Ermert and O. Kutzmutz, eds., Wie aufs Blatt kommt, was im Kopf steckt. Beiträge zum Kreativen Schreiben. Wolfenbüttel: Bundesakademie für kulturelle Bildung, 34-54.

. (2006): Medienlinguistik [Media Linguistics]. Konstanz: UVK.

Perrin, Daniel and Maureen Ehrensberger (submitted): "Progression analysis: Tracing journalistic language awareness".

Pitts, Beverley J. (1982): "Protocol analysis of the newswriting process". Newspaper Research Journal 4: 12-21.

Prior, Paul (2004): "Tracing process: How texts come into being". In C. Bazerman and P. Prior, eds., What writing does and how it does it: An introduction to analyzing texts and textual practice. Mahwah, NJ: Lawrence Erlbaum, 167-200.

Schmitt, Rudolf (2003): The Interaction between Research Method and Subjective Competence in Systematic Metaphor Analysis. Forum Qualitative Sozialforschung / Forum: Qualitative Social Research [on-line journal], 4(2).

[http://www.qualitative-research.net/fqs-texte/2-03/2-03schmitt-e.htm].

Schoonen, Rob and Kees de Glopper (1996): "Writing performance and knowledge about writing”. In G. Rijlaarsdam, H. van den Bergh, and M. Couzijn, eds., Theories, models and methodology in writing research. Amsterdam, Amsterdam University Press, 87-107.

Sleurs, Kim, Geert Jacobs, and Luuk van Waes (2003): "Constructing press releases, constructing 
quotations: A case study". Journal of Sociolinguistics 7: 135-275.

Spitzmüller, Jürgen (2005): Metasprachdiskurse. Einstellungen zu Anglizismen und ihre wissenschaftliche Rezeption [Metalinguistic discourse. Attitudes to anglicisms and their scientific reception]. Berlin: de Gruyter.

Tashakkori, Abbas and Charles Teddlie (2003). "Major issues and controversies in the use of mixed methods in social and behavioral research". In A. Tashakkori and C. Teddlie, eds., Handbook of Mixed Methods in Social and Behavioral Research. Thousand Oaks: Sage, 3-50.

Tuchman, Gaya (1991): "Qualitative methods in the study of news". In K.B. Jensen and N.W. Jankowski, eds., A handbook of qualitative methodologies for mass communication research. London: Routledge, 79-92.

van Waes, Luuk and Peter Schellens (2003): "Writing profiles: the effect of the writing mode on pausing and revision patterns of experienced writers". In D. Perrin, ed., The pragmatics of writing [Special Issue]. Journal of Pragmatics 35: 829-853. 